\title{
Effect of Thermal Treatment of the Hydroxyapatite Powders on the Micropore and Microstructure of Porous Biphasic Calcium Phosphate Composite Granules
}

\author{
David S. H. Lee*, Yuni Pai, Steve Chang \\ Department of Research and Development, SigmaGraft, Brea, USA. \\ Email: *davidlee@sigmagraft.com \\ Received January $20^{\text {th }}, 2013$; revised February $25^{\text {th }}, 2013$; accepted March $28^{\text {th }}, 2013$ \\ Copyright (C) 2013 David S. H. Lee et al. This is an open access article distributed under the Creative Commons Attribution License, \\ which permits unrestricted use, distribution, and reproduction in any medium, provided the original work is properly cited.
}

\begin{abstract}
The effect of thermal treatment of the hydroxyapatite powders on the micropore structure of porous biphasic calcium phosphate (BCP) granules was examined. The porous $\mathrm{BCP}$ granules could be attained through mixing and sintering/fracturing thermally treated $60 \mathrm{wt} \%$ hydroxyapatite powders and calcined $40 \mathrm{wt} \% \beta$-tricalcium phosphate powders. The observed Scanning electron microscopy (SEM) morphologies showed that the density of micropores $(0.1-2.0 \mu \mathrm{m})$ including interconnected micropores of the porous BCP granules mixed with hydroxyapatite powders thermally treated at $900^{\circ} \mathrm{C}$ was significantly improved and the composite particles of porous BCP granules were homogeneously mixed and distributed. This result indicates that the particles of hydroxyapatite powders that have a tendency to agglomerate at a room temperature were well isolated and dispersed through thermal treatment processing before mixing with calcined $\beta$-tricalcium phosphate powders. The microstructural characterizations such as phase purity and composition of porous $\mathrm{BCP}$ granules were performed and verified by X-ray diffraction (XRD) and Fourier transform infrared spectroscopy (FT-IR) analysis.
\end{abstract}

Keywords: BCP Composite; Hydroxyapatite; Thermal Treatment; Micropore Structure

\section{Introduction}

The application of calcium phosphate ceramics has become relatively to far and wide in the biomedical materials field, due to their biocompatibility with human hard tissue [1-5]. Of theses, the porous biphasic calcium phosphate ceramics $(\mathrm{BCP})$ generally comprise the intimate mix of non-resorbable hydroxyapatite $\left(\mathrm{HA}: \mathrm{Ca}_{10}\left(\mathrm{PO}_{4}\right)_{6}\right.$ $\left.(\mathrm{OH})_{2}\right)$ and resorbable $\beta$-tricalcium phosphate $(\beta$-TCP: $\beta$-Ca $\left.3\left(\mathrm{PO}_{4}\right)_{2}\right)[6,7]$. They are particularly suitable materials for synthetic bone substitute applications. The porous $\mathrm{BCP}$ offers a great potential for bone reconstruction via osteoconductivity (and in some special cases, osteoinductivity [8]) since it has the chemical composition close to biologic bone apatites. The multifactors such as chemical composition, resorption and dissolution rates, pore structure have an effect on the bone formation in bioceramic. The presence of a macroporous structure $(>100 \mu \mathrm{m})$ favors cell ingrowth while the microporosity $(<10 \mu \mathrm{m})$ allows the penetration of body fluids into the implant [9].

"Corresponding author.
Thus, the microporosity can be a strategy to manipulate resorption and dissolution rate: the greater the microporosity, the greater the degradation rate [10-14]. Specially, it has also been demonstrated that a high specific surface area, which can be achieved by increasing the number of micropores, is essential for osteoinductivity [15-20].

Therefore, in this study, we sintered the porous BCP composite scaffold compacted with thermally treated hydroxyapatite powders and calcined $\beta$-tricalcium phosphate powders to enhance the density of micropores. We also investigated the effect of thermal treatment of the hydroxyapatite powders on the pore structural and microstructural evolution of the porous $\mathrm{BCP}$ granules fractured from sintered porous BCP scaffold by using Scanning electron microscopy (SEM), X-ray diffraction (XRD), and Fourier transform infrared spectroscopy (FT-IR).

\section{Experimental}

The BCP composite powders were obtained by mechanical mixing and stirring with $60 \mathrm{wt} \%$ hydroxyapatite 
(from Spectrum, USA) powders and $40 \mathrm{wt} \% \beta$-tricalcium phosphate powders in a distilled water. The $\beta$-tricalcium phosphate powders were synthesized through a chemical precipitation reaction. $\mathrm{A} \mathrm{Ca}\left(\mathrm{NO}_{3}\right)_{2} \cdot 4 \mathrm{H}_{2} \mathrm{O}$ (from Sigma Aldrich, USA) solution was mixed and stirred with $\left(\mathrm{NH}_{4}\right)_{2} \mathrm{HPO}_{4}$ (from Science Lab, USA) solution to produce calcium-deficient apatite precipitates, and then the synthesized powders were calcined at $800^{\circ} \mathrm{C}$ for $12 \mathrm{hr}$ to transform from calcium-deficient apatite to $\beta$-tricalcium phosphate. Before mixing with $\beta$-tricalcium phosphate powders, the hydroxyapatite powders were thermally treated at $900^{\circ} \mathrm{C}$ for $2 \mathrm{hr}$. The obtained BCP powders were sieved, and then mechanically mixed with polyethylene glycol (PEG) particulates with the size of 150 $500 \mu \mathrm{m}$ as a pore forming agent to form macropores. The mixtures with $55 \mathrm{wt} \%$ PEG were pressed, uniaxially at $34 \mathrm{MPa}$ in a hardened steel die. The green disks with the diameter of $25 \mathrm{~mm}$ and the thickness of $5 \mathrm{~mm}$ were heattreated at $600^{\circ} \mathrm{C}$ for $1 \mathrm{hr}$ to remove an organic substances, and then they were sintered at $950^{\circ} \mathrm{C}$ for $1 \mathrm{hr}$, and then furnace-cooled to a room temperature. The porous BCP scaffold was fractured into the granule size range of 500 $-1000 \mu \mathrm{m}$ in a mortar and pestle.

The morphology and phase constitution of porous BCP composite granules were observed by Scanning electron microscopy (SEM, JSM-5600, Jeol), X-ray diffraction (XRD, D/MAX-2200/PC, Rigaku), and Fourier transform infrared spectroscopy (FT-IR, NICOLET, iS5, Thermo Scientific).

\section{Results and Discussion}

The pore structure and microstructure of both powders as a starting material before mixing and sintering with thermal treated hydroxyapatite powders and calcined $\beta$ tricalcium phosphate powders to synthesis porous biphasic calcium phosphate (BCP) granules were investigated. Thus, the SEM morphology of the hydroxyapatite powders non-thermal treated (Figure 1(a)), the hydroxyapatite powders thermal treated at $900^{\circ} \mathrm{C}$ (Figure 1(b)), and the $\beta$-tricalcium phosphate powders calcined at $800^{\circ} \mathrm{C}$ (Figure 1(c)) was observed, as shown in Figure 1. The particles of thermal treated hydroxyapatite powders in Figure 1(b) were well separated between particle and particle and their size was uniformly distributed to about $200 \mathrm{~nm}$, resulting in the significant increase of the number of micropores, comparing to those of non-thermal treated hydroxyapatite powders in Figure 1(a). This result indicates that the micropore density and surface area of hydroxyapatite powders were significantly enhanced through isolating agglomerated particles through thermal activation processing at a high temperature. The $\beta$-tricalcium phosphate powders in Figure 1(c) also showed good particle isolation, uniform particle size $(\sim 450 \mathrm{~nm})$ distribution, and micropore density improvement due to the effect of calcination that is the thermal processing for phase transformation.

Figure 2 shows the X-ray diffraction pattern for the hydroxyapatite powders thermal treated at $900^{\circ} \mathrm{C}$. The three dominant peaks such as $(211)\left(2 \theta=31.8^{\circ}\right),(112)$ $\left(2 \theta=32.2^{\circ}\right)$, and $(300)\left(2 \theta=32.9^{\circ}\right)$ are hydroxyapatite, which are verified by comparing data obtained with the PDF (Powder Diffraction File) pattern 09-0432. Also, as expected, the hydroxyapatite powders with a high crystallinity degree $(>97 \%)$ were obtained through thermal treating. The fraction of the crystalline phase (Xc) of hydroxyapatite powders was evaluated by following equation [21]:

$$
\mathrm{Xc}=100 \cdot \frac{\mathrm{I}_{300}-\mathrm{V}_{112 / 300}}{\mathrm{I}_{300}},[\%]
$$

where $I_{300}$ is the intensity of (300) diffraction peak and $\mathrm{V}_{112 / 300}$ is the intensity of hollow between (112) and (300) diffraction peaks of hydroxyapatite.

The hydroxyapatite powders were mixed and sintered with calcined $\beta$-tricalcium phosphate powders to prepare porous $\mathrm{BCP}$ composite granules. The BCP granules were obtained through fracturing sintered porous BCP scaffold.

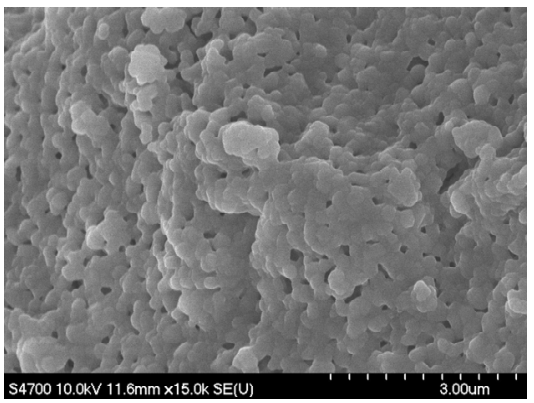

(a)

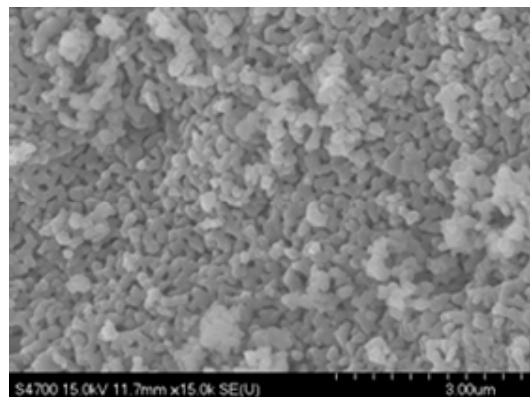

(b)

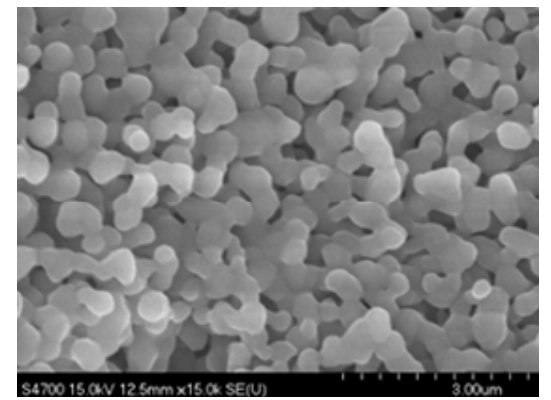

(c)

Figure 1. The SEM morphology of (a) the hydroxyapatite powders non-thermal treated, (b) the hydroxyapatite powders thermal treated at $900^{\circ} \mathrm{C}$ for $2 \mathrm{hr}$, and (c) the $\beta$-tricalcium phosphate powders calcined at $800^{\circ} \mathrm{C}$ for $12 \mathrm{hr}$. 
In order to investigate a thermal treatment effect of the hydroxyapatite powders on the pore structure and microstructure of synthesized porous BCP granules, the SEM morphology of the porous BCP granules mixed and sintered with non-thermal treated (Figure 3(a)) and thermal treated (Figures 3(b) and (c)) hydroxyapatite powders was observed, as shown in Figure 3. The composite particles of porous BCP granules in Figure 3(c) were homogeneously mixed and distributed with hydroxyapatite particles and $\beta$-tricalcium phosphate particles, resulting in the large surface area due to a high micropore density. It is considered that this is because the particles of hydroxyapatite powders were uniformly dispersed through treating thermally at a high temperature. On the other hand, the $\beta$-tricalcium phosphate particles were embedded in the matrix that is consist of agglomerated hydroxyapatite particles in porous BCP granules (Figure 3(a)). This result indicates that the particle structure of porous $\mathrm{BCP}$ granules results in obstructing the formation of the micropores associated with the permeation of bloods and body fluids into the implant [9] for the application of bone void filler. As indicated in Figures 3(b) and (c), the pore structure of porous BCP granules was composed of micropores $(100-500 \mathrm{~nm})$ and interconnected micropores $(0.9-2.0 \mu \mathrm{m})$, including the macropores ranged from 150 to $300 \mu \mathrm{m}$ (Figure 3(b)) and the micropores and macropores were fully interconnected.

Figure 4 shows the X-ray diffraction pattern of the porous BCP granules mixed and sintered with thermal treated hydroxyapatite powders. The diffraction widths of all peaks were sharp, indicating a good sinterability. Also, the porous $\mathrm{BCP}$ granules were highly crystalline due to the effect of the thermal treatment processing of hydroxyapatite powders before mixing and sintering with calcined $\beta$-tricalcium phosphate powders. It is considered that the thermal treated hydroxyapatite particles with a high crystallinity played a significant role in improving the crystallinity degree of porous $\mathrm{BCP}$ composite granules. The phase percentage of hydroxyapatite and $\beta$-tricalcium phosphate was $60 \% \pm 5 \%$ of hydroxyapatite in hydroxyapatite/ $\beta$-tricalcium phosphate and it was calculated by following equation [22]:

$$
\mathrm{HA}(\%)=100 \cdot \frac{\mathrm{I}_{211} \text { of } \mathrm{HA}}{\mathrm{I}_{211} \text { of } \mathrm{HA}+\mathrm{I}_{210} \text { of } \beta-\mathrm{TCP}}
$$

where $I_{211}$ and $I_{210}$ are the intensity of (211) diffraction peak of hydroxyapatite and the intensity of (210) diffraction peak of $\beta$-tricalcium phosphate, respectively.

The FT-IR spectrum of the porous BCP granules mixed and sintered with thermal treated hydroxyapatite powders is shown in Figure 5. The stretching vibration of the hydroxyl groups $\left(\mathrm{OH}^{-}\right)$that is the norm for majority of porous BCP granules was observed at around 3572 and $632 \mathrm{~cm}^{-1}$ and the orthophosphate $\left(\mathrm{PO}_{4}^{3-}\right)$ was also observed at $960-1120 \mathrm{~cm}^{-1}, 602 \mathrm{~cm}^{-1}$, and 570 $\mathrm{cm}^{-1}$, as indicated in Figure 5. From these results, it is clearly shown that the porous BCP granules were composed of hydroxyapatite and $\beta$-tricalcium phosphate and no other phases, that is, calcium oxide or $\alpha$-tricalcium phosphate, were found.

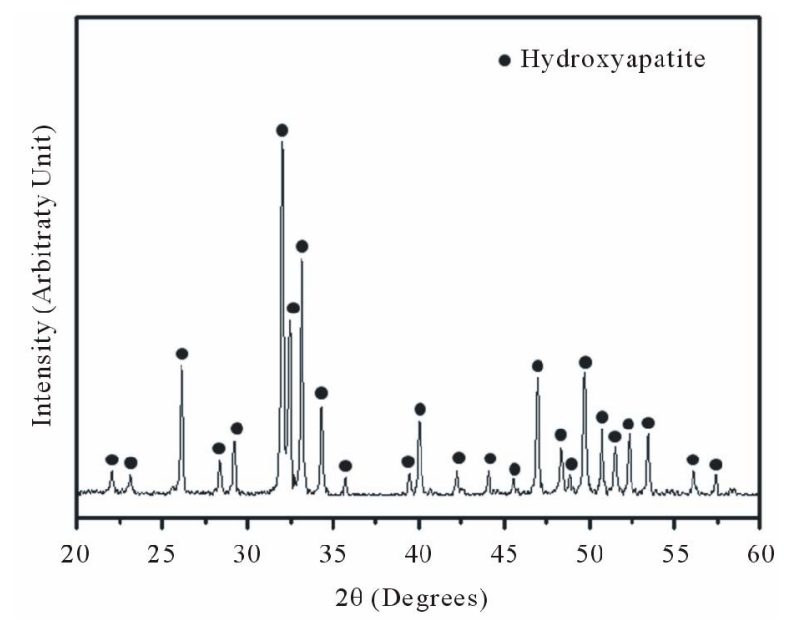

Figure 2. The X-ray diffraction (XRD) pattern for the hydroxyapatite powders thermal treated at $900^{\circ} \mathrm{C}$ for $2 \mathrm{hr}$.

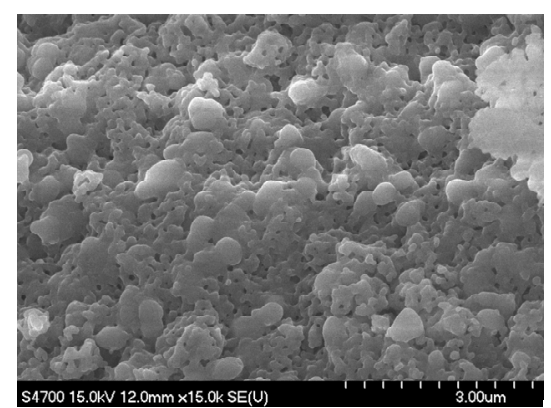

(a)

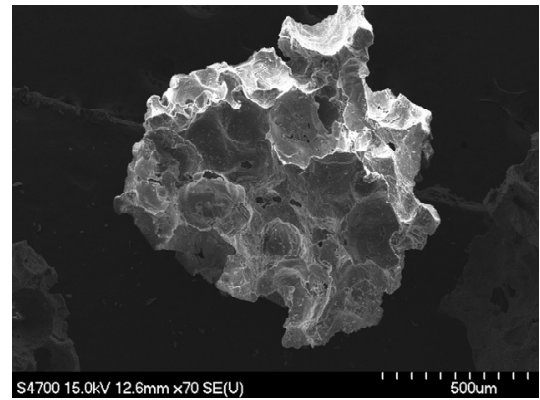

(b)

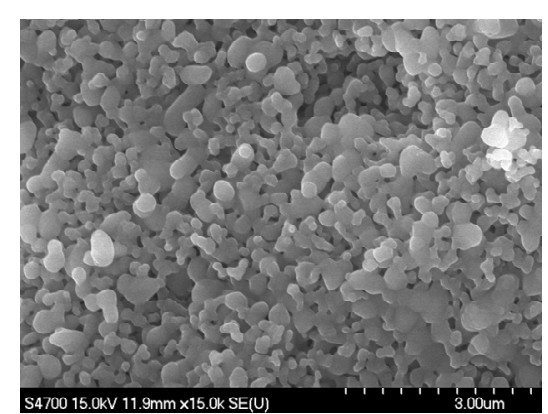

(c)

Figure 3. The SEM morphology of the porous BCP composite granules mixed and sintered with non-thermal treated hydroxyapatite powders (a) and thermal treated hydroxyapatite powders (b) and (c) at $900^{\circ} \mathrm{C}$ for 2 hr: (b) The SEM morphology $(\times 70)$ for macropore structure; (c) The SEM morphology $(\times 15,000)$ for micropore structure. 


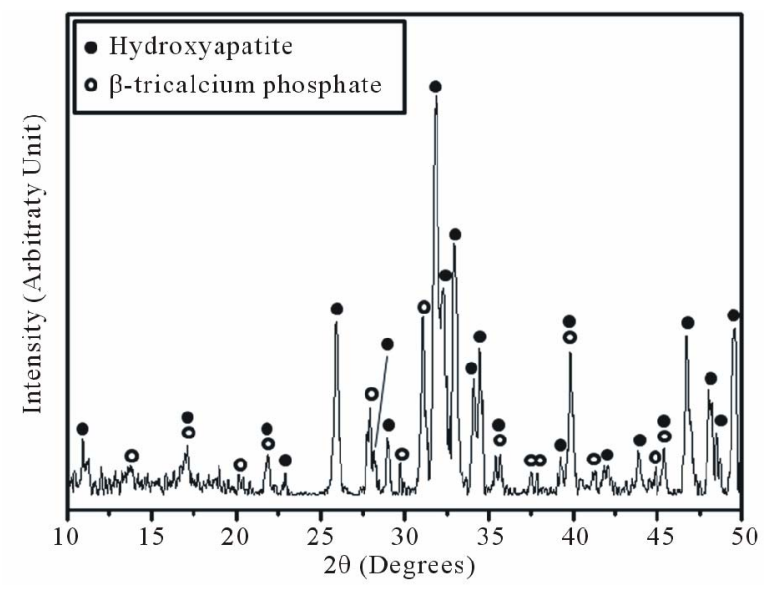

Figure 4. The X-ray diffraction pattern of the porous BCP composite granules mixed and sintered with thermal treated hydroxyapatite powders at $900^{\circ} \mathrm{C}$ for $2 \mathrm{hr}$.

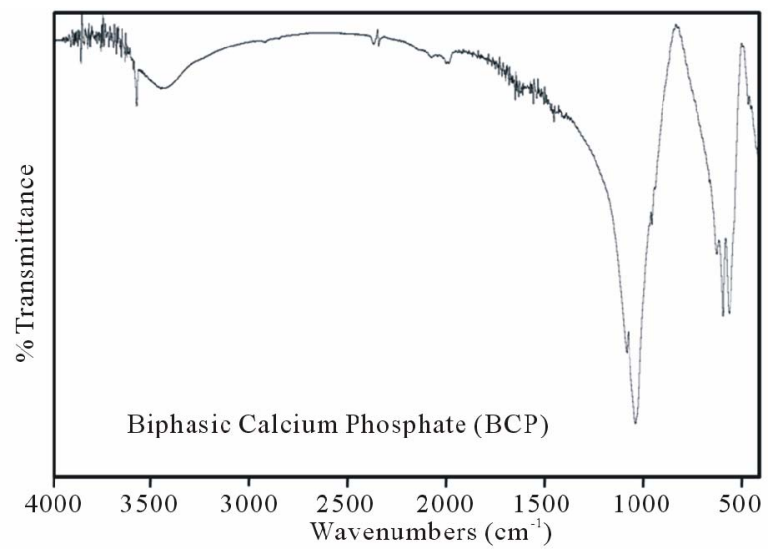

Figure 5. The FT-IR spectrum of the porous BCP composite granules mixed and sintered with thermal treated hydroxyapatite powders at $900^{\circ} \mathrm{C}$ for $2 \mathrm{hr}$.

\section{Conclusion}

In conclusions, the high density micropores including the interconnected micropores of porous BCP composite granules could be obtained through mixing and sintering the hydroxyapatite powders thermal treated and the $\beta$-tricalcium phosphate powders calcined. Also, the composite particles of porous BCP granules were homogeneously mixed and distributed with hydroxyapatite and $\beta$-tricalcium phosphate particles, comparing to those of the porous $\mathrm{BCP}$ granules with non-thermal treated hydroxyapatite powders. That the porous BCP granules were highly crystalline was verified by $\mathrm{X}$-ray diffraction and that they were composed of hydroxyapatite and $\beta$-tricalcium phosphate was confirmed by FT-IR analysis.

\section{REFERENCES}

[1] L. Yubao, C. P. A. T. Klein, J. Wijn, S. Meer and K.
Groot, "Shape Change and Phase Transition of NeedleLike Non-Stoichiometric Apatite Crystals," Journal of Materials Science: Materials in Medicine, Vol. 5, No. 5, 1994, pp. 263-268. doi:10.1007/BF00122395

[2] I. H. Arita, V. M. Castano and D. S. Wilkinson, "Synthesis and Processing of Hydroxyapatite Ceramic Tapes with Controlled Porosity," Journal of Materials Science: Materials in Medicine, Vol. 6, No. 1, 1995, pp. 19-23. doi:10.1007/BF00121241

[3] D. Liu, "Influence of Porosity and Pore Size on the Compressive Strength of Porous Hydroxyapatite Ceramic," Ceramics International, Vol. 23, No. 2, 1997, pp. 135139. doi:10.1016/S0272-8842(96)00009-0

[4] A. Tas, F. Korkusuz, M. Tumucin and N. Akkas, "An Investigation of the Chemical Synthesis and High-Temperature Sintering Behaviour of Calcium Hydroxyapatite (HA) and Tricalcium Phosphate (TCP) Bioceramics," Journal of Materials Science: Materials in Medicine, Vol. 8, No. 2, 1997, pp. 91-96.

[5] R. Rao, H. N. Roopa and T. S. Kannan, "Solid State Synthesis and Thermal Stability of HAP and HAP- $\beta$-TCP Composite Ceramic Powders," Journal of Materials Science: Materials in Medicine, Vol. 8, No. 8, 1997, pp. 511518. doi:10.1023/A:1018586412270

[6] G. Daculsi, R. Z. Legeros, E. Nery, K. Lynch and B. Kerebel, "Transformation of Biphasic Calcium Phosphate Ceramics in Vivo: Ultrastructural and Physicochemical Characterization," Journal of Biomedical Materials Research, Vol. 23, No. 8, 1989, pp. 883-894. doi: $10.1002 / \mathrm{jbm} .820230806$

[7] G. Daculsi, O. Laboux, O. Malard and P. Weiss, "Current State of the Art of Biphasic Calcium Phosphate Bioceramics," Journal of Materials Science: Materials in Medicine, Vol. 14, No. 3, 2003, pp. 195-200. doi:10.1023/A:1022842404495

[8] U. Ripamonti, "Osteoinduction in Porous Hydroxyapatite Implanted in Heterotopic Sites of Different Animal Models," Biomaterials, Vol. 17, No. 1, 1996, pp. 31-35. doi:10.1016/0142-9612(96)80752-6

[9] S. E. Lobo and T. L. Arinzeh, "Biphasic Calcium Phosphate Ceramics for Bone Regeneration and Tissue Engineering Applications," Materials, Vol. 3, No. 2, 2010, pp. 815-826. doi:10.3390/ma3020815

[10] O. Gauthier, J. M. Bouler, E. Aguado, R. Z. Legeros, P. Pilet and G. Daculsi, "Elaboration Conditions Influence Physicochemical Properties and in Vivo Bioactivity of Macroporous Biphasic Calcium Phosphate Ceramics," Journal of Materials Science: Materials in Medicine, Vol. 10, No. 4, 1999, pp. 199-204. doi:10.1023/A:1008949910440

[11] K. A. Hing, L. F. Wilson and T. Buckland, "Comparative Performance of Three Ceramic Bone Graft Substitutes," The Spine Journal, Vol. 7, No. 4, 2007, pp. 475-490. doi:10.1016/j.spinee.2006.07.017

[12] R. Z. Legeros, S. Lin, R. Rohanizadeh, D. Mijares and J. P. Legeros, "Biphasic Calcium Phosphate Bioceramics: Preparation, Properties and Appications," Journal of Materials Science: Materials in Medicine, Vol. 14, No. 3, 
2003, pp. 201-209. doi:10.1023/A:1022872421333

[13] K. A. Hing, B. Annaz, S. Saeed, P. A. Revell and T. Buckland, "Microprosity Enhances Bioactivity of Synthetic Bone Graft Substitutes," Journal of Materials Science: Materials in Medicine, Vol. 16, No. 5, 2005, pp. 467-475. doi:10.1007/s10856-005-6988-1

[14] M. Mastrogiacomo, S. Scaglione, R. Martinetti, L. Dolcini, F. Beltrame, R. Cancedda and R. Quarto, "Role of Scaffold Internal Structure on in Vivo Bone Formation in Macroporous Calcium Phosphate Bioceramics," Biomaterials, Vol. 27, No. 17, 2006, pp. 3230-3237. doi:10.1016/j.biomaterials.2006.01.031

[15] G. Daculsi and R. Legeros, "Encyclopedia of Biomaterials and Biomedical Engineering," Marcel Dekker Inc., New York, 2006, p. 1.

[16] P. Habibovic, T. M. Sees, M. A. Doel, C. A. Blitterswijk and K. Groot, "Osteoinduction by Biomaterials-Physicochemical and Structural Influences," Journal of Biomedical Materials Research Part A, Vol. 77A, No. 4, 2006, pp. 747-762. doi:10.1002/jbm.a.30712

[17] H. Yuan, K. Kurashima, J. D. Bruijn, Y. Li, K. Groot and X. Zhang, "A Preliminary Study on Osteoinduction of Two Kinds of Calcium Phosphate Ceramics," Biomaterials, Vol. 20, No. 19, 1999, pp. 1799-1806. doi:10.1016/S0142-9612(99)00075-7

[18] G. Daculsi and P. Layrolle, "Osteoinductive Properties of
Micro Macroporous Biphasic Calcium Phosphate Bioceramics," Key Engineering Materials, Vol. 254-256, 2004, pp. 1005-1008.

doi:10.4028/www.scientific.net/KEM.254-256.1005

[19] D. L. Nihouannen, G. Daculsi, A. Saffarzadeh, O. Gauthier, S. Delplace, P. Pilet and P. Layrolle, "Ectopic Bone Formation by Microporous Calcium Phosphate Ceramic Particles in Sheep Muscles,” Bone, Vol. 36, No. 6, 2005, pp. 1086-1093. doi:10.1016/j.bone.2005.02.017

[20] P. Habibovic, H. Yuan, C. M. Valk, G. Meijer, C. A. Blitterswijk and K. Groot, "3D Microenvironment as Essential Element for Osteoinduction by Biomaterials," Biomaterials, Vol. 26, No. 17, 2005, pp. 3565-3575. doi:10.1016/j.biomaterials.2004.09.056

[21] E. Landi, A. Tampieri, G. Celotti and S. Sprio, "Densification Behaviour and Mechanisms of Synthetic Hydroxyapatites," Journal of the European Ceramic Society, Vol. 20, No. 14-15, 2000, pp. 2377-2387. doi:10.1016/S0955-2219(00)00154-0

[22] L. Zhang, N. Hanagata, M. Maeda, T. Minowa, T. Ikoma, H. Fan and X. Zhang, "Porous Hydroxyapatite and Biphasic Calcium Phosphate Ceramics Promote Ectopic Osteoblast Differentiation from Mesenchymal Stem Cells," Science and Technology of Advanced Materials, Vol. 10, No. 2, 2009, Article ID: 025003. doi:10.1088/1468-6996/10/2/025003 